\title{
Alcohol, tobacco and breast cancer - collaborative reanalysis of individual data from 53 epidemiological studies, including 58515 women with breast cancer and 95067 women without the disease
}

\author{
Collaborative Group on Hormonal Factors in Breast Cancer*,1 \\ 'Secretariat, Cancer Research UK Epidemiology Unit, Gibson Building, Radcliffe Infirmany, Woodstock Road, Oxford OX2 6HE, UK
}

Alcohol and tobacco consumption are closely correlated and published results on their association with breast cancer have not always allowed adequately for confounding between these exposures. Over 80\% of the relevant information worldwide on alcohol and tobacco consumption and breast cancer were collated, checked and analysed centrally. Analyses included 58515 women with invasive breast cancer and 95067 controls from 53 studies. Relative risks of breast cancer were estimated, after stratifying by study, age, parity and, where appropriate, women's age when their first child was born and consumption of alcohol and tobacco. The average consumption of alcohol reported by controls from developed countries was 6.0 g per day, i.e. about half a unit/drink of alcohol per day, and was greater in ever-smokers than never-smokers, (8.4 g per day and $5.0 \mathrm{~g}$ per day, respectively). Compared with women who reported drinking no alcohol, the relative risk of breast cancer was $1.32(1.19-1.45$, $P<0.0000 \mathrm{I})$ for an intake of $35-44 \mathrm{~g}$ per day alcohol, and 1.46 ( I.33- I.6I, $P<0.0000 \mathrm{I})$ for $\geqslant 45 \mathrm{~g}$ per day alcohol. The relative risk of breast cancer increased by $7.1 \%(95 \% \mathrm{Cl} 5.5-8.7 \%$; $P<0.0000 \mathrm{I})$ for each additional $\mathrm{I} 0 \mathrm{~g}$ per day intake of alcohol, i.e. for each extra unit or drink of alcohol consumed on a daily basis. This increase was the same in ever-smokers and never-smokers (7.1\% per $10 \mathrm{~g}$ per day, $P<0.0000 \mathrm{I}$, in each group). By contrast, the relationship between smoking and breast cancer was substantially confounded by the effect of alcohol. When analyses were restricted to 22255 women with breast cancer and 40832 controls who reported drinking no alcohol, smoking was not associated with breast cancer (compared to never-smokers, relative risk for ever-smokers $=1.03,95 \% \mathrm{Cl} 0.98-1.07$, and for current smokers $=0.99,0.92-1.05$ ). The results for alcohol and for tobacco did not vary substantially across studies, study designs, or according to 15 personal characteristics of the women; nor were the findings materially confounded by any of these factors. If the observed relationship for alcohol is causal, these results suggest that about $4 \%$ of the breast cancers in developed countries are attributable to alcohol. In developing countries, where alcohol consumption among controls averaged only $0.4 \mathrm{~g}$ per day, alcohol would have a negligible effect on the incidence of breast cancer. In conclusion, smoking has little or no independent effect on the risk of developing breast cancer; the effect of alcohol on breast cancer needs to be interpreted in the context of its beneficial effects, in moderation, on cardiovascular disease and its harmful effects on cirrhosis and cancers of the mouth, larynx, oesophagus and liver.

British Journal of Cancer (2002) 87, 1234 - 1245. doi:I0.1038/sj.bjc.6600596 www.bjcancer.com

(c) 2002 Cancer Research UK

Keywords: breast cancer; alcohol; tobacco; smoking; collaborative reanalysis

Many epidemiological studies have investigated the relationship between breast cancer and the consumption of alcohol and/or tobacco. References to over 80 studies that have collected relevant data, as well as to reviews of the subject, are given in Appendix II (www. bjcancer.com). The published results from these studies have generally suggested that women who regularly consume alcohol may be at a slightly increased risk of the disease, but the findings reported for tobacco are inconsistent. Alcohol and tobacco consumption are known to be associated one with another, and published results have not always allowed adequately for possible confounding between

* Correspondence: Valerie Beral, Secretariat, Cancer Research UK Epidemiology Unit, Gibson Building, Radcliffe Infirmary, Oxford OX2 6HE, UK (See Appendix I for list of collaborators)

Received 12 June 2002; revised 8 August 2002; accepted 23 August 2002 these exposures. Individual data from 65 epidemiological studies of breast cancer 63 published $^{1-63}$ and two unpublished in which information on alcohol and/or tobacco consumption had been collected contributed to this collaboration. These studies, some of which have not published results for alcohol or tobacco, include over $80 \%$ of the worldwide information on the topic (see Appendix II (www.bjcancer.com)). The data from these studies were analysed, taking careful account of the possible confounding between alcohol and tobacco consumption, as well as confounding by other factors.

\section{METHODS}

\section{Eligibility of studies and collection of data}

Data from epidemiological studies of women with breast cancer have been brought together by the Collaborative Group on 
Hormonal Factors in Breast Cancer to describe the relationship between breast cancer and various reproductive, hormonal and other factors. ${ }^{64,65}$ Case-control and cohort studies were eligible for the collaboration if they included at least 100 women with incident invasive breast cancer and recorded information on reproductive factors and on use of hormonal therapies. Cohort studies were included using a nested case-control design, in which four controls were selected at random, matched on follow-up to the age of the case at diagnosis and, where appropriate, broad geographical region. Data for individual women were collated and analysed centrally so that analyses could be carried out using as similar definitions across studies as was possible. Details sought from principal investigators of each participating study included data that had been collected on each woman's reproductive history and various other factors that may be relevant to the aetiology of breast cancer, including the women's consumption of alcohol and tobacco.

Some investigators provided estimates of alcohol intake reported by each woman expressed as gram (g) of alcohol consumed per day or per week. Others provided information on the reported number of alcoholic drinks consumed daily or weekly. In such instances, the number of grams of alcohol consumed per day, was estimated assuming that one alcoholic drink contains $12 \mathrm{~g}$ alcohol in the USA and Italy, ${ }^{11} 8 \mathrm{~g}$ in the UK and $10 \mathrm{~g}$ elsewhere (Brewers' Society, personal communication). No information was sought about alcohol consumption at various ages or about the particular type of alcohol consumed. Information was also sought on whether or not each woman had ever smoked, and whether she was a current or past smoker. Active smoking only was considered and no attention given to the reported associations with environmental tobacco smoke, ${ }^{35,49}$ nor was information sought on the age women were when smoking started or stopped, or on the amount smoked. The methods of identifying studies and of data checking, and correction, have been described elsewhere. ${ }^{64,65}$

\section{Statistical analysis and presentation of results}

Statistical methods were similar to those used in previous reports by this group. ${ }^{64-67}$ Data from different studies were combined by means of the Mantel-Haenszel stratification technique, the stratum-specific quantities calculated being the standard 'observed minus expected' $(\mathrm{O}-\mathrm{E})$ numbers of women with breast cancer, together with their variances and covariances. These values yield both statistical descriptions (odds ratios, subsequently referred to as relative risks) and statistical tests ( $P$ values). When only two groups are being compared, relative risk estimates are obtained from $\mathrm{O}-\mathrm{E}$ values by the one-step method, ${ }^{66}$ as are their standard errors (SE) and confidence intervals (CI). When more than two groups are compared, variances are estimated by treating the relative risks as floating absolute risks (FARs). ${ }^{67}$ This approach yields floated standard errors (FSE) and floated confidence intervals (FCI). Presentation of the results in this way enables valid comparisons between any two exposure groups, even if neither is the baseline group. Any comparison between groups must take the variation in each estimate into account by summing the variances of the logarithms of the two FARs.

To obtain comparability between the women with breast cancer and similar women without breast cancer, all analyses were routinely stratified by study, and centre within study; by age (in single years from 16 to 64,65 to 69,70 to 74 , etc., up to 85 to 89 ); by parity and, where appropriate, age when the first child was born (nulliparous women were assigned to a separate stratum and parous women were cross-classified according to parity $(1-2,3-$ $4,5-6,7+)$ and age at first birth $(<20,20-24,25-29,30+))$. Where appropriate analyses relating to alcohol consumption were stratified by smoking history (ever/never) and analyses relating to tobacco consumption were stratified by alcohol consumption $(0$, $<5,5-14,15-24,25-34,35-44, \geqslant 45$ g per day). In order to summarise the relationship between alcohol consumption and breast cancer risk, a linear trend in the log relative risk of breast cancer was fitted across increasing categories of consumption. In estimating such trends, the median consumption within a given category was taken to be the level of alcohol consumption for that category.

In general, results in the text are presented as relative risks and their appropriate SE or FSEs. Where results are presented in the form of plots, relative risks and their corresponding CIs/FCIs are represented by squares and lines, respectively. The position of the square indicates the value of the relative risk and its area is inversely proportional to the variance of the logarithm of the relative risk, thereby providing an indication of the amount of statistical information available for that particular estimate. Owing to the large number of relative risk estimates calculated, results are given with their appropriate 99\% CIs/FCIs; and 95\% CIs/FCIs are used only to summarise the main findings.

The absolute risk of breast cancer associated with various levels of alcohol consumption was estimated for women in developed countries, by applying the dose-response estimates obtained here to age-specific incidence rates for breast cancer in developed countries around $1990^{64,65}$ assuming that an intake of $10 \mathrm{~g}$ per day is roughly equivalent to one unit or drink of alcohol per day. The cumulative incidence of breast cancer up to age 80 years was calculated from the age-specific findings.

\section{RESULTS}

The 65 studies that contributed individual data on alcohol and/ or tobacco consumption and other factors relevant to breast cancer included a total of 66426 women with invasive breast cancer (cases) and 126953 women without breast cancer controls from 63 published $^{1-63}$ and two unpublished studies. Information on both alcohol and tobacco had been collected in 53 of these studies, that included a total of 58515 cases and 95067 controls from 51 published $^{1-51}$ and two unpublished studies. Unless otherwise specified, analyses presented here are restricted to data from these 53 studies. This enables women to be cross-classified by both their alcohol and tobacco consumption, thus permitting adequate examination of possible confounding between the two exposures.

Among women with breast cancer in the 53 studies included in the main analyses, the median year of diagnosis was 1988 and the average age at diagnosis was 52.1 years. All but five of the 53 studies $5,9,21,41,48$ were conducted in developed countries. Among controls, alcohol consumption was substantially greater in women from developed than developing countries (average alcohol intakes of $6.0 \mathrm{~g}$ per day and $0.4 \mathrm{~g}$ per day, respectively). The proportion of controls from developed countries who reported drinking no alcohol was $40 \%$, and a further $28 \%$ reported consuming $<5$ g per day, i.e. less than half a unit/drink of alcohol per day (Table 1). Only about $1 \%$ of the controls from developed countries reported drinking 35-44 g per day alcohol, i.e. about four units or drinks daily, and a similar proportion reported drinking $\geqslant 45 \mathrm{~g}$ per day.

Overall about half the women in developed countries reported that they had ever smoked, but smoking habits varied considerably according to alcohol intake, both for cases and controls (Table 1). Among controls from developed countries who reported drinking no alcohol, $37 \%$ had ever smoked, and the proportion of ever-smokers increased with increasing intake of alcohol, rising to $73 \%$ for controls who reported drinking $\geqslant 45 \mathrm{~g}$ per day alcohol (Table 1 ). The average alcohol consumption reported by ever-smokers from developed countries was greater than that reported by never-smokers ( $8.4 \mathrm{~g}$ per day $v s$ $5.0 \mathrm{~g}$ per day). 
Table I Reported alcohol and tobacco consumption among cases and controls in developed countries for whom information on both factors was available

\begin{tabular}{lcccccccc}
\hline & \multicolumn{7}{c}{ Alcohol consumption (g per day) } \\
\cline { 2 - 8 } & $\mathbf{0}$ & $\mathbf{1 - 4}$ & $\mathbf{5 - 1 4}$ & $\mathbf{1 5 - 2 4}$ & $\mathbf{2 5 - 3 4}$ & $\mathbf{3 5 - 4 4}$ & $\mathbf{4 5 +}$ & Total \\
\hline CASES & & & & & & & & \\
$\quad$ Number (\%) & $18331(36)$ & $13785(27)$ & $10238(20)$ & $3444(6.8)$ & $2522(5.0)$ & $954(1.9)$ & $1192(2.4)$ & $50466(100)$ \\
$\quad$ Per cent that ever-smoked & $39 \%$ & $48 \%$ & $58 \%$ & $60 \%$ & $56 \%$ & $64 \%$ & $70 \%$ & $49 \%$ \\
$\begin{array}{l}\text { CONTROLS } \\
\quad \text { Number (\%) }\end{array}$ & & & & & & & \\
$\quad$ Per cent that ever-smoked & $31872(40)$ & $22654(28)$ & $15484(19)$ & $5082(6.3)$ & $2727(3.4)$ & $1119(1.4)$ & $1067(1.3)$ & $80005(100)$ \\
\hline
\end{tabular}

Table 2 Relative risk ${ }^{\mathrm{a}}$ of breast cancer in relation to reported intake of alcohol, according to smoking history

\begin{tabular}{lccc}
\hline $\begin{array}{l}\text { g per day alcohol } \\
\text { consumption } \\
\text { (median) }\end{array}$ & $\begin{array}{c}\text { Never-smoker } \\
\text { relative risk }^{\mathbf{a}} \\
\text { (FSE) }\end{array}$ & $\begin{array}{c}\text { Ever-smoker } \\
\text { relative risk } \\
\text { (FSE) }\end{array}$ & $\begin{array}{c}\text { All women } \\
\text { relative risk }^{\mathbf{a}} \\
\text { (FSE) }\end{array}$ \\
\hline $0(0)$ & $1.00(0.015)$ & $1.00(0.018)$ & $1.00(0.012)$ \\
$<5(2)$ & $1.01(0.020)$ & $1.01(0.020)$ & $1.01(0.014)$ \\
$5-14(8)$ & $1.01(0.023)$ & $1.05(0.021)$ & $1.03(0.015)$ \\
$15-24(18)$ & $1.19(0.048)$ & $1.09(0.035)$ & $1.13(0.028)$ \\
$25-34(29)$ & $1.22(0.056)$ & $1.19(0.047)$ & $1.21(0.036)$ \\
$35-44(39)$ & $1.18(0.093)$ & $1.40(0.077)$ & $1.32(0.059)$ \\
$\geqslant 45(58)$ & $1.49(0.110)$ & $1.46(0.072)$ & $1.46(0.060)$ \\
$\begin{array}{l}\text { Increase in the relative } \\
\text { risk of breast cancer }\end{array}$ & & & \\
$\quad$ per 10 g per day (SE) & $7.1 \%(1.3 \%)$ & $7.1 \%(0.9 \%)$ & $7.1 \%(0.8 \%)$ \\
\hline
\end{tabular}

${ }^{a}$ Calculated as floating absolute risk (FAR), with corresponding floated standard error (FSE), and stratified by study, age, parity, age at first birth and, for 'all women', by smoking history (see Methods).

Because alcohol and tobacco consumption are so closely associated, analyses of their effects were initially carried out separately for never-smokers and ever-smokers (in the case of alcohol) and for drinkers and non-drinkers (in the case of tobacco).

\section{Breast cancer in relation to alcohol consumption}

Table 2 shows the relative risks and corresponding standard errors for breast cancer according to women's reported daily intake of alcohol for never-smokers and ever-smokers. In each group the relative risk of breast cancer increased significantly with increasing intake of alcohol, increasing by the same amount, $7.1 \%$, for each additional $10 \mathrm{~g}$ per day intake of alcohol $(P<0.00001$ in each group). The trends associated with increasing levels of alcohol intake in never-smokers and ever-smokers did not differ significantly from each other $\left(\chi^{2}{ }_{1}\right.$ for heterogeneity $\left.=0.002 ; P=1.0\right)$. Therefore subsequent analyses concerning alcohol consumption include both never-smokers and ever-smokers, and the data are stratified by smoking history as well as by study, age, parity and age at first birth.

When the data in smokers and non-smokers were combined the relative risk of breast cancer increased with alcohol intake, increasing by $7.1 \%$ (SE $0.8 \% ; P<0.00001$ ) for each additional $10 \mathrm{~g}$ per day intake of alcohol, i.e. for each extra unit/drink of alcohol consumed on a daily basis (Figure 1). Compared to women who drank no alcohol the relative risk was $1.32(0.059, P<0.00001)$ for women whose reported alcohol consumption was 35-44 g per day and $1.46(0.060, P<0.00001)$ for a consumption of $\geqslant 45 \mathrm{~g}$ per day, where the average consumption was $57 \mathrm{~g}$ per day.

The study-specific results are summarised in Figure 2, grouped according to study design. Studies which contributed the smallest amounts of statistical information, were grouped together as 'other' in each of these categories. There was no strong evidence to suggest that the results varied substantially across studies $\left(\chi^{2}{ }_{52}=60.7 ; P=0.3\right)$ or according to study design $\left(\chi_{2}^{2}\right.$ for heterogeneity $=1.5 ; P=0.5)$. In the one study ${ }^{52}$ which contributed data on alcohol, but not smoking, the estimated increase in the relative risk of breast cancer per additional $10 \mathrm{~g}$ per day intake was $13.8 \%$ (SE 10.5\%). Because of the large standard error, the estimated increase in relative risk in this study does not differ significantly from results for all other studies combined $\left(\chi_{1}^{2}=0.4, P=0.5\right)$

The effect of adjusting for 11 other potential confounding factors (race, education, family history of breast cancer, age at menarche, height, weight, body mass index, breastfeeding, use of hormonal preparations, and age at and type of menopause) on the relationship in Figure 1 is shown in Table 3. Additional adjustment for each of these factors in turn did not materially alter the magnitude of the increase in the relative risk of breast cancer associated with increasing levels of alcohol intake, suggesting that the associations in Figure 1 are not much confounded by any of them.

\section{Breast cancer in relation to tobacco consumption}

Among the 22255 cases and 40832 controls who reported drinking no alcohol, the risk of breast cancer in ever-smokers did not differ significantly from that in never-smokers (relative risk for ever vs never-smokers=1.03, SE 0.023; NS). However, among women who reported drinking alcohol, the findings for smoking were difficult to disentangle from the effects of the alcohol itself. When eversmokers were compared to never-smokers the relative risk for breast cancer was $1.09(0.018)$ before stratification by the amount of alcohol consumed, and declined to $1.05(0.020)$ after stratification. The corresponding $\chi^{2}{ }_{1}$ value declined by three-quarters from 23.4 to 6.4 . Since alcohol consumption is known to be unreliably measured, ${ }^{68}$ and stratification for such a poorly measured variable reduced the $\chi^{2}$ value by three-quarters, stratification by true alcohol intake would be expected to reduce the $\chi^{2}$ value by even more. ${ }^{69}$ Since it is not possible to eliminate residual confounding among drinkers, results concerning tobacco consumption are restricted to women who reported drinking no alcohol at all, where such confounding should be minimised.

The study-specific relative risks for breast cancer in ever-smokers compared to never-smokers are shown in Figure 3, for women who reported drinking no alcohol. There was no marked variation in the relative risk of breast cancer across studies $\left(\chi_{52}^{2}=58.0, P=0.3\right)$ or study design $\left(\chi_{2}^{2}=6.1, P=0.05\right)$. Information on current and past smoking was available for all but five studies. ${ }^{2,23,28}$ (and two unpublished). Among ever-smokers in the remaining 48 studies 54\% were current smokers and $46 \%$ were past smokers. Compared to neversmokers the relative risk of breast cancer was 0.99 (SE 0.03) for current smokers (Appendix III (www.bjcancer.com)), and 1.07 (SE 0.03) for past smokers (Appendix IV (www.bjcancer.com)). 


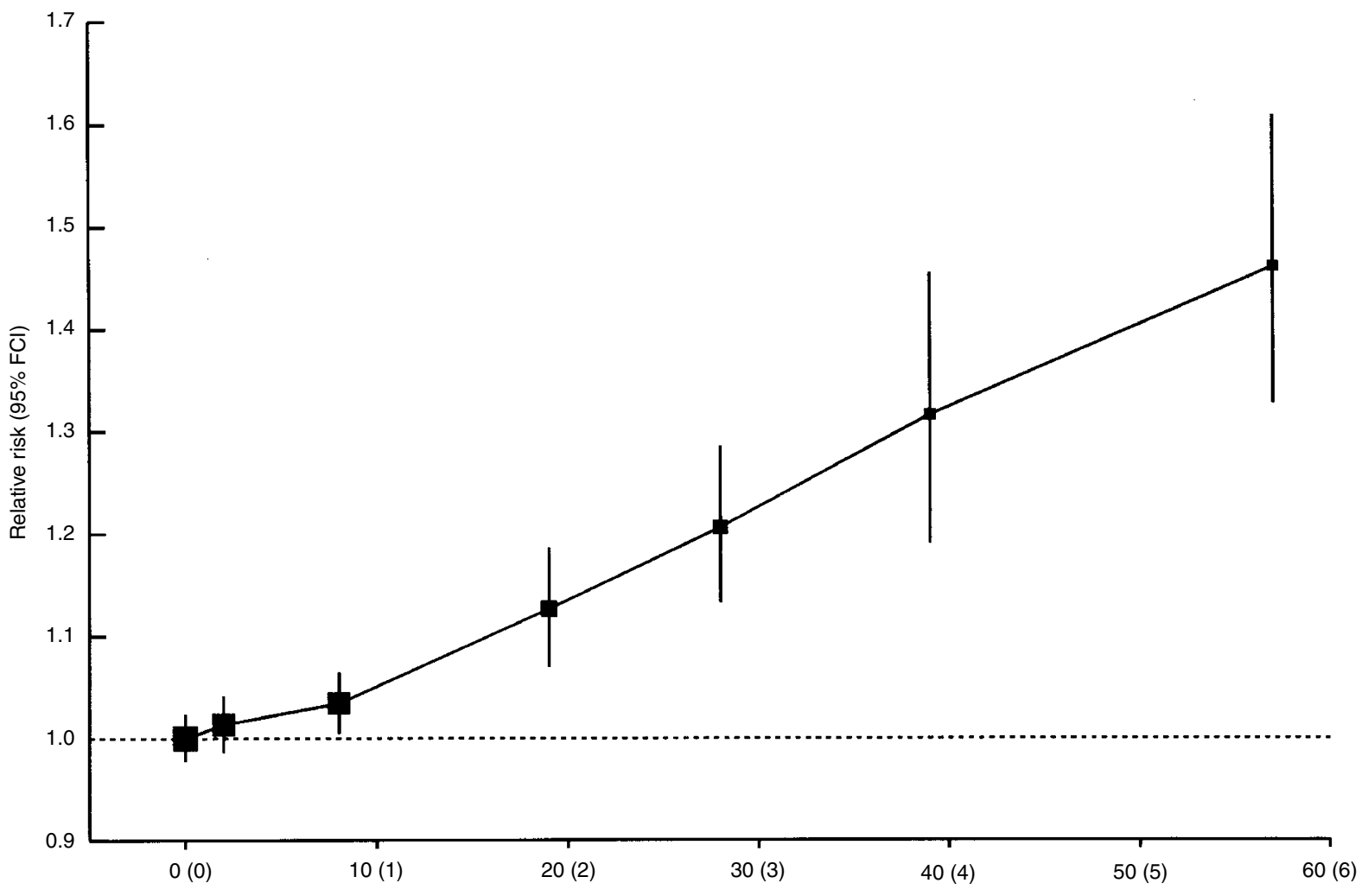

Self-reported alcohol consumption, g per day ( number drinks daily)

Figure I Relative risk of breast cancer in relation to reported intake of alcohol. Relative risks are calculated as floating absolute risk (FAR) and stratified by study, age, parity, age at first birth and smoking.

Among controls from developed countries a greater proportion of ever-smokers than never-smokers had had a bilateral oophorectomy $(8.7 \%$ vs $7.6 \%)$ or a hysterectomy without bilateral oophorectomy $(13.3 \%$ vs $12.5 \%)$. The average age at bilateral oophorectomy was 41.6 (SD 7.5) and 44.2 (SD 6.6), respectively and the average age at hysterectomy was 38.6 (SD 9.3) and 40.0 (SD 9.9), respectively. Average age at natural menopause was also slightly earlier in ever-smokers than in never smokers, at 48.3 (SD 4.8) and 49.3 (SD 4.7) years, respectively. The relative risk of breast cancer in ever $v s$ never-smokers was similar for women who had had an oophorectomy, hysterectomy or natural menopause (Table 4) and additional stratification by age at and type of menopause did not materially alter the overall magnitude of the relative risk (Table 3). Nor did additional stratification by 10 other potential confounding factors much alter the relative risk.

Eleven studies ${ }^{53-63}$ that together included a total of 4781 cases and 12713 controls, contributed data to this collaboration on tobacco consumption for each woman, but not on alcohol consumption. The combined relative risk of breast cancer in ever-smokers compared to never-smokers in these 11 studies was 1.05 (SE 0.05), but because of the potential for confounding by alcohol the results from these studies have not been included in the main analyses.

\section{Consistency of the findings}

The increase in the relative risk of breast cancer for each additional $10 \mathrm{~g}$ per day intake of alcohol consumption was calculated separately for various subgroups of women, subdivided according to 15 personal characteristics including their age, childbearing pattern, race and familial patterns of breast cancer. Overall there was no significant variation in the trend associated with increasing intake of alcohol between categories defined by any of the 15 factors examined (Figure 4: global test for heterogeneity $\left.\chi_{15}^{2}=18.0 ; P=0.3\right)$. Nor was there significant variation in the relative risk of breast cancer associated with having ever smoked across categories of the 15 characteristics examined (Figure 4: global test for heterogeneity $\chi_{15}^{2}=17.9$; $P=0.3$ ).

Information on the extent of spread of the breast cancer was available for about $60 \%$ of the study population. Both for tumours localised to the breast and for tumours that had spread beyond the breast, the risk of breast cancer increased with increasing alcohol consumption (increase in relative risk of breast cancer of $6.9 \%(1.3 \%)$ and $9.4 \%(1.5 \%)$, respectively, per $10 \mathrm{~g}$ per day alcohol consumption: $\left.\chi^{2}{ }_{1}=3.3 ; P=0.07\right)$. There was no significant difference in the extent of tumour spread among the cases according to tobacco consumption $\left(\chi_{1}^{2}=3.0\right.$, $P=0.08)$.

\section{Cumulative incidence of breast cancer}

Around 1990 the cumulative incidence of breast cancer up to age 80 years was between about eight and 10 per 100 women in developed countries. ${ }^{64,65,70}$ The average consumption of alcohol by controls studied here from developed countries was $6.0 \mathrm{~g}$ per day. If the dose-response relationship described here is valid, it is 


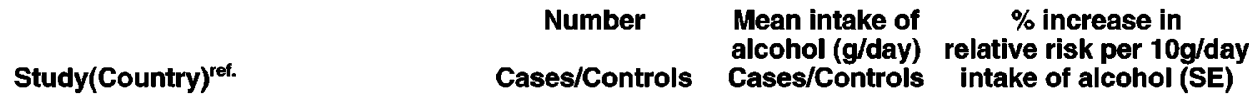

COHORT STUDIES:

Nurses Health Study(USA)
Canadian NBSS(Canada) ${ }^{64}$
American Cancer Society $(\text { USA })^{51}$
Netherlands Cohort(Netherlands)
lowa Womens Health(USA) $^{33}$
Million Women Study (UK)
Other
Ot,13,26,41

$2870 / 11480$
$753 / 2857$
$1196 / 4829$
$470 / 1686$
$1188 / 4752$
$1436 / 5744$
$1780 / 7083$

All cohort studies

$9693 / 38431$

\section{CASE-CONTROL, POPULATION CONTROLS:}

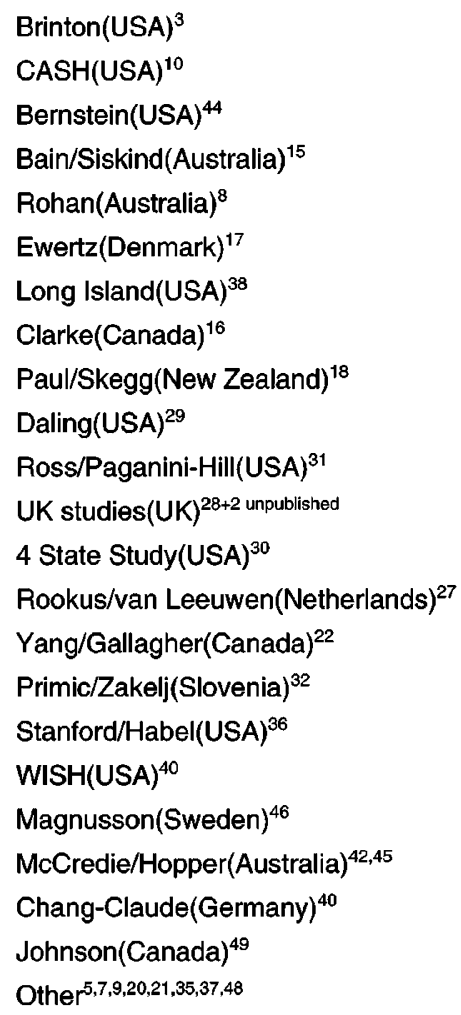

1726/2179

$4455 / 4672$

$676 / 676$

$487 / 981$

$451 / 451$

$1525 / 1398$

$1183 / 1184$

$607 / 1214$

$888 / 1857$

$747 / 961$

$1055 / 1092$

$1871 / 1871$

$6880 / 9525$

$918 / 918$

$1019 / 1025$

$619 / 619$

$450 / 492$

$1866 / 2007$

$3168 / 3285$

$1581 / 1021$

$656 / 1283$

2338/2427

$3509 / 4656$

All case-control, pop controls

$6.3 / 5.2$
$9.2 / 8.9$
$9.5 / 9.0$
$6.3 / 5.8$
$4.1 / 3.5$
$5.6 / 5.2$
$0.8 / 0.4$
$5.0 / 4.4$

$8.7 / 7.2$

$8.2 / 7.4$

$6.9 / 5.6$

$6.7 / 5.6$

$7.0 / 4.5$

$7.4 / 7.2$

$5.9 / 4.6$

$8.5 / 7.6$

$3.8 / 3.4$

$7.4 / 6.8$

$7.7 / 6.5$

$5.6 / 5.8$

$6.6 / 5.3$

$10.6 / 9.6$

4.9/5.2

$3.7 / 2.0$

$6.4 / 5.4$

6.0/6.6

$2.7 / 2.2$

$6.9 / 6.0$

$10.8 / 8.5$

$5.2 / 6.2$

$2.1 / 2.4$

$6.0 / 5.3$

3.1/3.5

$14.2 / 12.2$

$8.9 / 6.4$

17.3/14.1

4.4/4.1

$14.5 / 8.5$

$12.5 / 9.4$

$7.0 / 5.4$
$4.4(2.5)$

$1.2(4.1)$

$7.0(5.3)$

$2.8(6.9)$

8.1 (4.8)

9.8 (6.3)

34.7 (41.5)

5.0 (1.7)

$3.7(4.0)$

3.5 (2.8)

$10.0(7.4)$

$-1.2(9.7)$

$4.9(10.6)$

$4.3(5.0)$

$15.8(7.7)$

$3.6(6.8)$

$7.3(11.4)$

$-0.6(5.2)$

$8.6(5.3)$

$1.2(5.1)$

$13.4(2.2)$

$5.6(4.8)$

$1.1(9.0)$

14.5 (13.8)

$-1.0(9.8)$

$-1.8(5.4)$

19.7 (8.4)

$8.3(6.4)$

$14.8(5.0)$

$6.6(4.5)$

$9.4(7.0)$

7.4 (1.1)

$-7.4(7.6)$

$3.2(2.6)$

$20.6(6.3)$

$9.5(2.5)$

$20.0(13.7)$

9.7 (8.4)

7.3 (1.7)

$7.1(0.8)$
$\%$ increase in relative risk of breast cancer per $10 \mathrm{~g} /$ day intake of alcohol \& $99 \% \mathrm{Cl}$

\begin{tabular}{|c|c|c|c|}
\hline Vessey $(\mathrm{UK})^{12}$ & $1125 / 1125$ & $3.1 / 3.5$ & $-7.4(7.6)$ \\
\hline Franceschi(Italy) ${ }^{4,43}$ & $2929 / 2963$ & $14.2 / 12.2$ & $3.2(2.6)$ \\
\hline Lê/Gerber/Clavel(France) $)^{2,14,39}$ & $1204 / 1724$ & $8.9 / 6.4$ & $20.6(6.3)$ \\
\hline La Vecchia(Italy) $)^{11}$ & $3623 / 2729$ & $17.3 / 14.1$ & $9.5(2.5)$ \\
\hline Katsouyanni(Greece) $)^{25}$ & $795 / 1548$ & $4.4 / 4.1$ & $20.0(13.7)$ \\
\hline Other ${ }^{23,34}$ & $471 / 753$ & $14.5 / 8.5$ & $9.7(8.4)$ \\
\hline All case-control, hospital controls & $10147 / 10842$ & $12.5 / 9.4$ & $7.3(1.7)$ \\
\hline ALL STUDIES & $58515 / 95067$ & $7.0 / 5.4$ & $7.1(0.8)$ \\
\hline
\end{tabular}

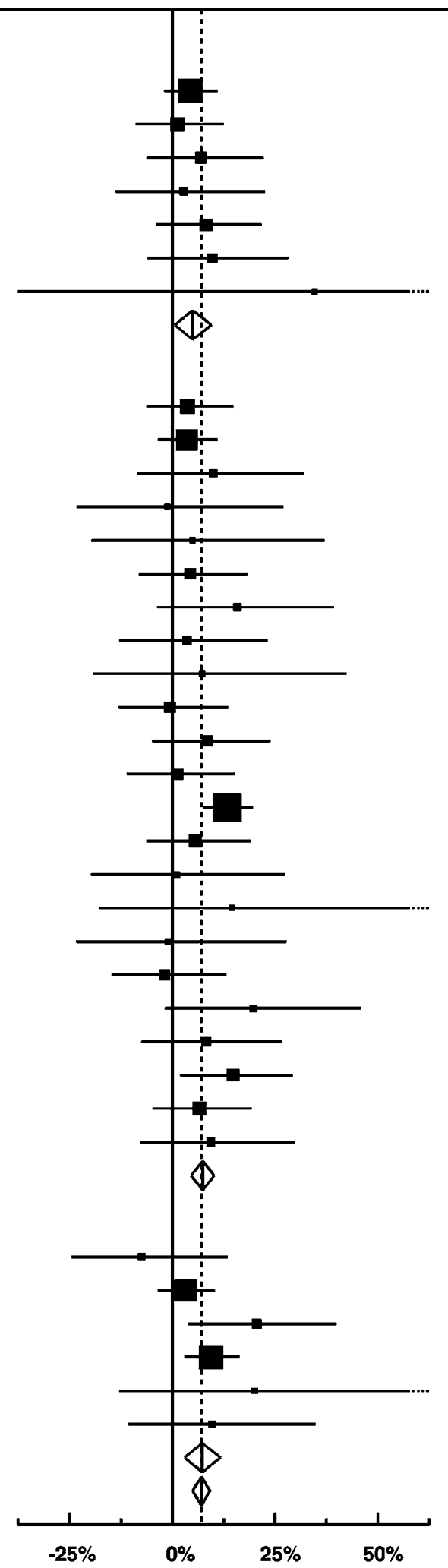

Figure 2 Details of and results from studies on the relation between alcohol consumption and breast cancer. Relative risks are stratified by age, parity, age at first birth and smoking history. 


\begin{tabular}{|c|c|c|c|c|}
\hline Study(Country) (ret. $^{\text {ret }}$ & $\begin{array}{c}\text { Number } \\
\text { Cases/Controls }\end{array}$ & $\begin{array}{c}\% \text { ever } \\
\text { smoked } \\
\text { Cases/Controls }\end{array}$ & $\begin{array}{c}\text { Relative rlsk of breast } \\
\text { cancer in ever- versus } \\
\text { never-smokers (SE) }\end{array}$ & $\begin{array}{c}\text { Relatlve rlsk of breast cancer } \\
\text { in ever- versus never-smokers } \\
\& 99 \% \mathrm{Cl}\end{array}$ \\
\hline
\end{tabular}

\section{COHORT STUDIES:}

Nurses Health Study(USA)

Canadian NBSS(Canada) ${ }^{24}$

American Cancer Society(USA) ${ }^{51}$

Netherlands Cohort(Netherlands) ${ }^{33}$

lowa Womens Health(USA) ${ }^{19}$

Million Women Study(UK) ${ }^{47}$

Other ${ }^{1,13,26,41}$

All cohort studies

$\begin{array}{cc}1224 / 5599 & 49 / 49 \\ 181 / 662 & 35 / 35 \\ 213 / 922 & 34 / 33 \\ 119 / 504 & 27 / 30 \\ 679 / 2765 & 25 / 26 \\ 324 / 1291 & 50 / 44 \\ 1923 / 7655 & 4 / 5 \\ 4663 / 19398 & 25 / 26\end{array}$

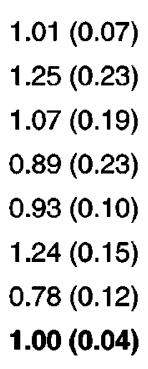

\section{CASE-CONTROL, POPULATION CONTROLS:}

Brinton(USA) ${ }^{3}$

CASH(USA) $)^{10}$

Bernstein(USA) ${ }^{44}$

Bain/Siskind(Australia) ${ }^{15}$

Rohan(Australia) ${ }^{8}$

Ewertz(Denmark) ${ }^{17}$

Long Island(USA) ${ }^{38}$

Clarke $\left(\right.$ Canada) ${ }^{16}$

Paul/Skegg(New Zealand) ${ }^{18}$

Daling(USA) ${ }^{29}$

Ross/Paganini-Hill(USA) ${ }^{31}$

UK studies $(U K)^{28+2}$ unpublished

4 State Study(USA $)^{30}$

Rookus/van Leeuwen(Netherlands) ${ }^{27}$

Yang/Gallagher(Canada) ${ }^{22}$

Primic/Zakelj(Slovenia) ${ }^{32}$

Stanford/Habel(USA) ${ }^{36}$

WISH(USA) ${ }^{40}$

Magnusson(Sweden) ${ }^{46}$

McCredie/Hopper(Australia) ${ }^{42,45}$

Chang-Claude(Germany) ${ }^{40}$

Johnson(Canada) ${ }^{49}$

Other $r^{5,7,9,20,21,35,37,48}$

All case-control, pop controls
649/872

$1817 / 1821$

$336 / 317$

$248 / 514$

$188 / 213$

227/198

$153 / 208$

$114 / 211$

$538 / 1058$

$211 / 286$

$578 / 590$

655/662

1507/2247

247/247

$505 / 517$

$115 / 128$

$152 / 181$

$353 / 241$

$1311 / 1312$

$774 / 518$

168/251

974/1110

2851/3567

14671/17269

$29 / 26$
$49 / 43$
$50 / 48$
$32 / 29$
$35 / 32$
$59 / 57$
$37 / 34$
$40 / 42$
$43 / 41$
$42 / 42$
$53 / 52$
$47 / 45$
$39 / 39$
$52 / 51$
$48 / 44$
$29 / 30$
$52 / 49$
$59 / 68$
$32 / 33$
$38 / 36$
$46 / 52$
$42 / 40$
$11 / 13$
$36 / 35$

CASE-CONTROL, HOSPITAL CONTROLS:

Vessey $(\text { UK })^{12}$

Franceschi(Italy $)^{4,43}$

Lê/Gerber/Clavel(France) 2,14,39

La Vecchia(Italy) ${ }^{11}$

Katsouyanni(Greece) ${ }^{25}$

Other ${ }^{23,34}$

All case-control, hospital controls ALL STUDIES

$\begin{array}{ccc}154 / 171 & 44 / 53 & 0.71(0.30) \\ 831 / 1025 & 31 / 31 & 1.01(0.12) \\ 492 / 923 & 18 / 24 & 0.82(0.16) \\ 980 / 1034 & 28 / 30 & 0.82(0.10) \\ 219 / 462 & 21 / 24 & 1.28(0.29) \\ 245 / 550 & 20 / 26 & 0.72(0.25) \\ 2921 / 4165 & 27 / 29 & 0.89(0.06) \\ 22255 / 40832 & 33 / 30 & 1.03(0.02)\end{array}$

$1.12(0.14)$

$1.28(0.08)$

$1.18(0.20)$

$1.31(0.26)$

$1.06(0.31)$

$0.88(0.27)$

$0.99(0.32)$

$0.88(0.31)$

$1.09(0.13)$

$0.87(0.21)$

$1.02(0.13)$

$1.08(0.13)$

$1.07(0.09)$

$0.90(0.21)$

$1.15(0.17)$

$0.67(0.38)$

$0.79(0.26)$

$0.63(0.21)$

$0.91(0.08)$

$1.03(0.15)$

$0.94(0.25)$

$1.14(0.11)$

$0.99(0.12)$

$1.07(0.03)$

$1.03(0.02)$
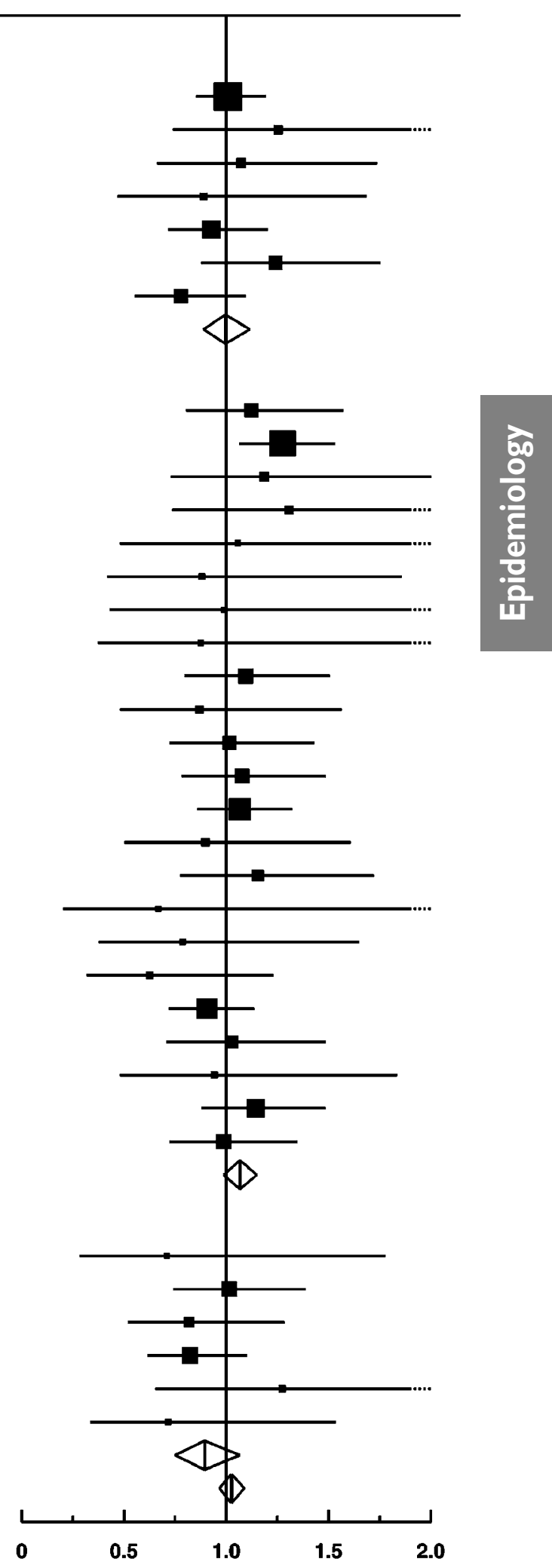

Figure 3 Details of and results on the relation between tobacco consumption and breast cancer in women who reported drinking no alcohol. Relative risks are stratified by age, parity and age at first birth. 
Table 3 Effect of additional adjustment for various factors on the relative risk of breast cancer associated with alcohol and tobacco consumption

\begin{tabular}{|c|c|c|}
\hline & $\begin{array}{l}\text { Per cent increase (SE) in the relative risk of } \\
\text { breast cancer per } 10 \mathrm{~g} \text { per day alcohol intake }\end{array}$ & $\begin{array}{l}\text { Relative risk (SE) of breast cancer in } \\
\text { ever-smokers, compared to never-smokers } \\
\text { for women who reported drinking no alcohol }\end{array}$ \\
\hline $\begin{array}{l}\text { After stratification for study, age, parity, age at } \\
\text { first birth and, for analyses concerning } \\
\text { alcohol, tobacco consumption }\end{array}$ & $7.1 \%(0.8 \%)$ & $1.03(0.02)$ \\
\hline \multicolumn{3}{|l|}{ After additional stratification for: } \\
\hline race & $7.2 \%(0.8 \%)$ & $1.03(0.02)$ \\
\hline education & $7.3 \%(0.8 \%)$ & $1.04(0.03)$ \\
\hline mother or sister with breast cancer & $7.2 \%(0.8 \%)$ & $1.02(0.03)$ \\
\hline age at menarche & $7.4 \%(0.8 \%)$ & $1.04(0.03)$ \\
\hline height & $7.5 \%(0.8 \%)$ & $1.02(0.03)$ \\
\hline weight & $7.2 \%(0.8 \%)$ & $1.04(0.03)$ \\
\hline body mass index & $6.9 \%(0.8 \%)$ & $1.04(0.03)$ \\
\hline breastfeeding & $6.9 \%(0.8 \%)$ & $1.02(0.02)$ \\
\hline ever use of hormonal contraceptives & $6.6 \%(0.8 \%)$ & $1.02(0.03)$ \\
\hline ever use of hormone replacement therapy & $7.3 \%(0.8 \%)$ & $1.02(0.03)$ \\
\hline type of and age at menopause & $7.2 \%(0.8 \%)$ & $1.06(0.03)$ \\
\hline
\end{tabular}

estimated that about $4 \%$ of breast cancers in developed countries are attributable to alcohol. The cumulative incidence of breast cancer by age 80 years is estimated to increase from 8.8 per 100 women in non-drinkers to $9.4,10.1,10.8,11.6,12.4$ and 13.3, respectively, per 100 women consuming an average of $1,2,3,4$, 5 and 6 alcoholic drinks each day (see Figure 5). In developing countries, where alcohol consumption is very low, averaging only about $0.4 \mathrm{~g}$ per day, alcohol would make a negligible contribution to the total number of cases of breast cancer.

\section{DISCUSSION}

There is potential for confounding between the possible effects of alcohol and of tobacco on breast cancer, as drinking and smoking are closely associated, one with another. Among controls from developed countries, the proportion of ever-smokers rose from $37 \%$ in women who reported drinking no alcohol at all, to $73 \%$ in women drinking $\geqslant 45 \mathrm{~g}$ per day alcohol, and alcohol consumption was greater in ever-smokers than in never-smokers, averaging 8.4 and 5.0 g per day, respectively.

The relative risk of breast cancer was found to increase with increasing intake of alcohol, both in never-smokers and in eversmokers, and the magnitude of the increase was the same in each group (an increase of $7.1 \%$ in the relative risk of breast cancer for each additional $10 \mathrm{~g}$ per day alcohol; 95\% CI $5.5-8.7 \%$ $P<0.00001$ overall). The observed association between breast cancer and alcohol consumption is therefore unlikely to be an indirect effect of tobacco.

Conversely, the relationship between smoking and breast cancer was found to be confounded by alcohol. Among women who drank no alcohol, ever-smokers and current smokers were not at an increased risk of breast cancer compared to neversmokers. Among women who drank alcohol, however, adjustment of the relative risk of breast cancer by the amount of alcohol consumed had a substantial effect on the results and, since it is not possible to measure alcohol intake reliably and thus eliminate residual confounding due to alcohol, we chose to base our assessment of the effect of tobacco on breast cancer on the 22255 cases and 40832 controls recorded as drinking no alcohol at all. In this large group of women the results suggest that smoking has little or no independent effect on the risk of developing breast cancer.

The association between breast cancer and alcohol or tobacco consumption does not appear to be materially confounded by the effects of other factors. Potential confounding by age, study, parity, age at first birth and tobacco consumption were minimised by stratification. Ever-smokers had their natural menopause about 1 year earlier, on average than never-smokers and were also more likely to have had a bilateral oophorectomy or hysterectomy, but adjustment for type of and age at menopause had little effect on the relative risk of breast cancer in ever- $v s$ never-smokers (Tables 3 and 4). In addition, possible confounding by race, education, family history of breast cancer, age at menarche, height, weight, body mass index, breastfeeding and use of hormonal preparations was examined by adjustment for each factor in turn, but none materially altered the estimates of relative risk (Table 3). Since the relative risk estimates for breast cancer in relation to both alcohol and tobacco consumption did not appear to differ substantially according to any of these factors, there is no strong evidence for interaction between either of these exposures and the 15 factors examined (Figure 4).

There was no significant difference in the extent of tumour spread according to either alcohol or tobacco consumption, suggesting that there is little differential detection of breast cancer or effect on tumour growth by these exposures.

\section{Combining results from different studies}

Combining results across many studies has the advantage of yielding estimates of the relative risk that are not subject to as much

Table 4 Relative risk of breast cancer in ever vs never smokers, according to menopausal status, in women who reported drinking no alcohol. Relative risks are stratified by study, age, parity and age at first birth

\begin{tabular}{lc}
\hline Menopausal status & Relative risk (SE) \\
\hline Premenopausal & $1.07(0.05)$ \\
Natural menopause & $1.11(0.15)$ \\
before age 45 years & $0.98(0.08)$ \\
at age $45-49$ years & $1.12(0.06)$ \\
at age $\geqslant 50$ years & \\
Bilateral oophorectomy & $0.78(0.16)$ \\
before age 45 years & $0.82(0.15)$ \\
at age $\geqslant 45$ years & $1.08(0.09)$ \\
Hysterectomy before menopause & \\
\hline
\end{tabular}

$\chi_{6}^{2}$ for heterogeneity $=7.5 ; P=0.9$ 

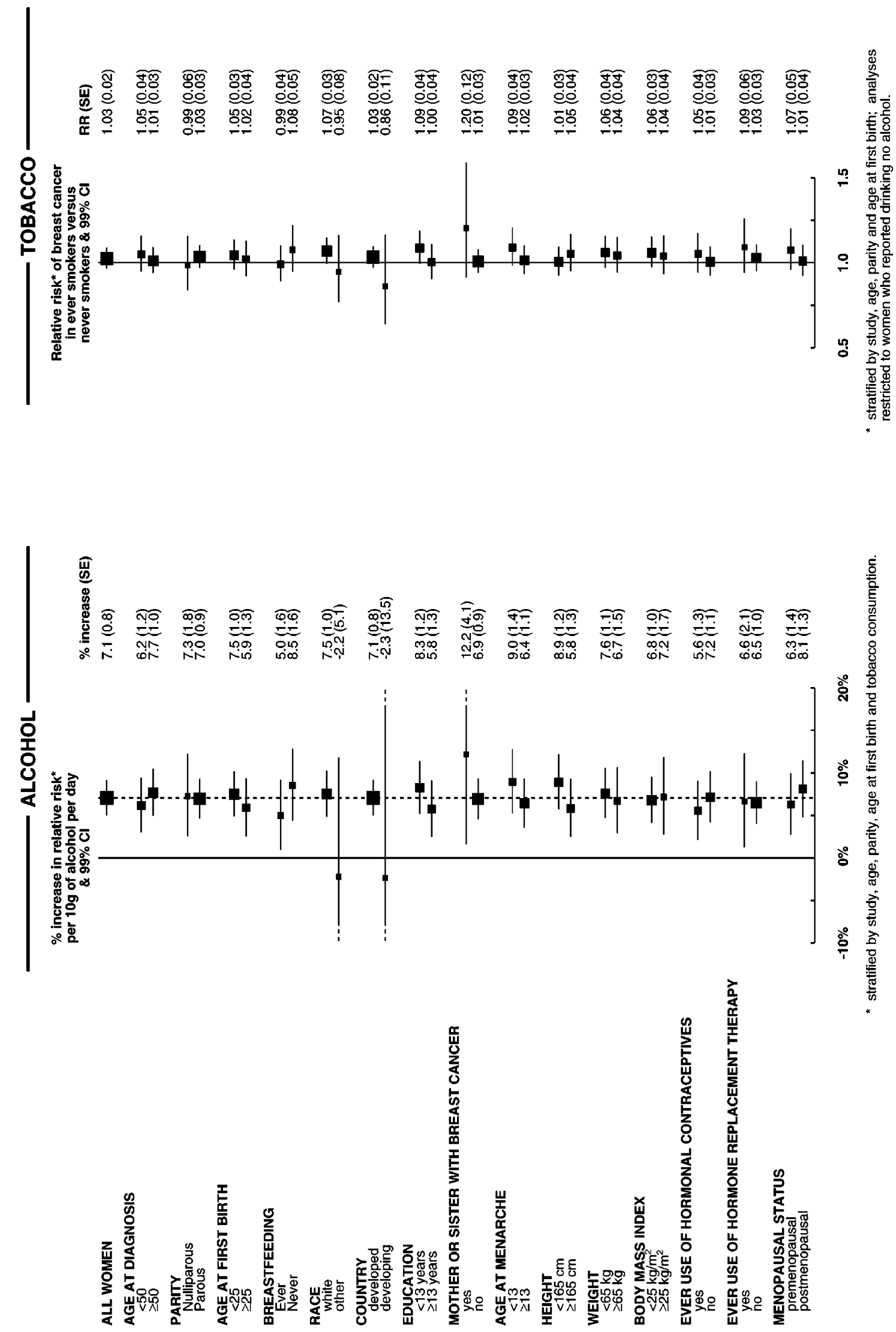

Figure 4 Relative risk of breast cancer in relation to alcohol and tobacco consumption in various subgroups of women. 


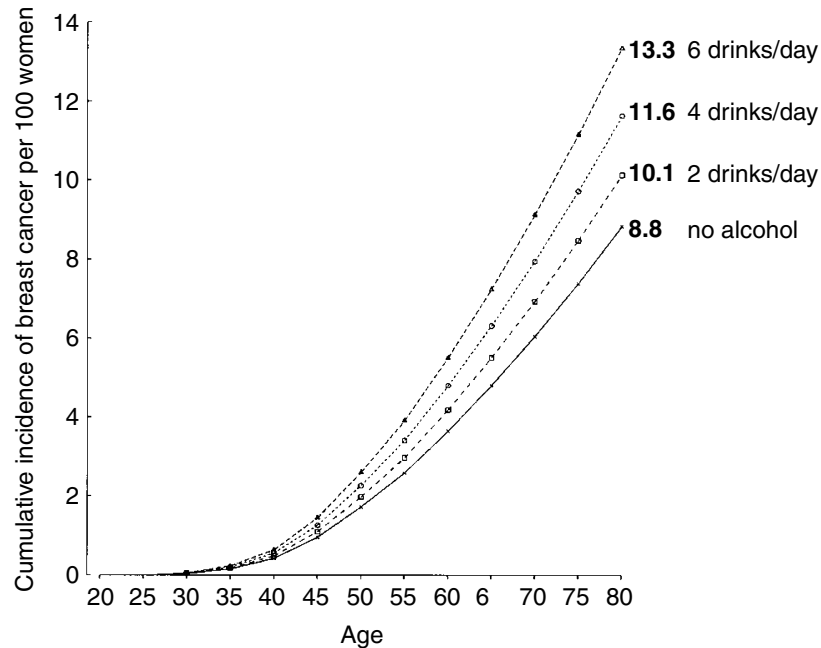

Figure 5 Estimated cumulative incidence of breast cancer per 100 women in developed countries, according to the number of alcoholic drinks consumed each day (see Methods).

random fluctuation as that found in any individual study. The studies that contributed to these findings were of different designs and included women with a wide range of alcohol and tobacco consumption and of other personal characteristics. Nevertheless, the relationships between breast cancer and alcohol and tobacco were seen consistently across studies and study designs, and for women of different ages, different childbearing histories, and for women who differed according to various other personal characteristics. The results were not unduly influenced by any particular study or groups of studies.

Because of the strong association between alcohol and tobacco consumption, the main analyses were restricted to data from the 53 studies in which information on both exposures had been collected in the same women. Results from the only study ${ }^{52}$ that had provided individual data on alcohol, but not tobacco, did not differ significantly from the overall findings for breast cancer and alcohol. The remaining 11 studies ${ }^{53-63}$ that provided individual data on tobacco, but not on alcohol, could not contribute directly to this review, since it was not possible to take into account for the important confounding effect of alcohol. None of the publications from these 11 studies has, however, claimed that smoking affected the risk of breast cancer.

As far as can be ascertained, over $80 \%$ of the worldwide epidemiological data that have been assembled on the relationship between breast cancer and alcohol and tobacco consumption were contributed to this collaboration. Another 20 studies were identified with relevant data that together included about 12000 women with breast cancer (see Appendix II (www.bjcancer.com)), but because results were presented in a different way in each study, it is difficult to combine the published data directly. Nevertheless, out of the six largest studies all but one (reference number 66, in Appendix II (www.bjcancer.com)) reported a statistically significant increased risk of breast cancer with increasing intake of alcohol. Each of these six studies included at least 500 women with breast cancer and altogether they comprised most of the information that had not been contributed in this collaboration. The remaining 14 studies were comparatively small and none of their published results on alcohol differed substantially from those reported here. Therefore the findings on alcohol and breast cancer from studies not included here do not appear to differ materially from these results.

Only one of the 20 studies that had not contributed to this collaboration claimed that smoking is associated with an increased risk breast cancer (reference number 81, in Appendix II (www.bjcancer.com)). None of these studies has, however, published results on the risk of breast cancer in relation to smoking, restricted to women who never drank alcohol.

\section{Limitations of these findings}

Overall, the relative risk of breast cancer appeared to increase by $7.1 \%(95 \%$ CI $5.5-8.7 \%)$ for each additional $10 \mathrm{~g}$ per day intake of alcohol i.e. for each extra unit/drink of alcohol consumed on a daily basis. Information on alcohol consumption was, however, usually self-reported, describing drinking habits at around the time that the women were interviewed. No information on the pattern of intake, including the type of alcohol consumed and the duration of intake, was collected for this collaboration. There is no strong evidence here to suggest biased reporting of alcohol consumption in case-control studies, since there was no significant difference in results between case-control and cohort studies (increases of $7.4 \%$ and $5.0 \%$ per $10 \mathrm{~g}$ per day, respectively; $\chi^{2}{ }_{1}$ for heterogeneity $=1.5, P=0.2$ ). However, self-reported information on alcohol consumption is known to underestimate true consumption. ${ }^{68}$ Systematic under-reporting of consumption by both cases and controls would result in an overestimation of the relative risk of breast cancer for a given level of alcohol consumption. By contrast, random misclassification among both cases and controls would have the opposite effect, resulting in an underestimation of the relative risk. These two types of measurement error are inevitable, but counter-acting, and it is not possible to estimate their overall effect on the relative risks calculated here. Moreover, the shape of the dose-response relationship could be changed if, for example, heavy drinkers were more likely to under-report intake than moderate drinkers. Taken together, these reporting errors imply that some uncertainty remains about the true quantitative effect of an intake of a fixed amount of alcohol on the risk of developing breast cancer.

The true relationship between alcohol consumption and breast cancer might, perhaps, be more curved than is suggested by the shape of the relationship shown in Figure 1, because of misclassification of alcohol intake, as may also have occurred with cigarette smoking and lung cancer. ${ }^{71}$ Any firm conclusion about the risk of breast cancer at low levels of alcohol intake is, however, prohibited by the likelihood of measurement errors, particularly the tendency for underestimation of the amount drunk, and by the possibility that non-drinkers may differ in some relevant, but unmeasured, ways from those who sometimes drink alcohol. Hence, the possibility of a threshold dose of alcohol cannot be reliably assessed from the data in Figure 1.

These results provide no direct evidence about possible mechanisms of carcinogenesis by alcohol on the breast. There is, however, accumulating evidence that regular intakes of moderate amounts of alcohol affect sex hormone levels. For example, the results of a recently published small randomised trial of 51 postmenopausal women suggested that sex hormone levels may be increased after the consumption of $30 \mathrm{~g}$ per day alcohol for 8 weeks, ${ }^{72}$ levels of consumption that are associated here with a clear excess risk of breast cancer.

With respect to the consumption of tobacco, the main exposure variable examined here was whether or not a woman had ever smoked. No information was collected for this collaboration on the amount smoked or on the age that smoking started or stopped, nor has attention been given to the reported effects of environmental exposure to tobacco, ${ }^{35,49}$ as active smoking only has been considered. Although some past smokers may have smoked relatively infrequently, current smokers are likely to have had substantial lifetime exposures to tobacco, particularly in countries where lung cancer rates in women are high. Just over half the ever-smokers included in these analyses were current smokers, 
and among them the risk of breast cancer was similar to that in never-smokers (relative risk $=0.99$ ( $95 \% \mathrm{CI}, 0.96-1.03)$ ). The findings from case-control studies could, in theory, be biased if women with breast cancer stopped smoking when they first developed symptoms, or if there were differential reporting of smoking by cases and controls. However, the results from cohort studies, where exposure information was collected prospectively, suggest no increase in the risk of breast cancer in ever-smokers or current smokers compared to never-smokers (relative risk $=1.00,95 \% \mathrm{CI}$ $0.93-1.07$, for ever-smokers; and $=0.94,95 \%$ CI $0.84-1.05$, for current smokers).

\section{Public health implications}

If the pattern of breast cancer associated with increasing levels of alcohol consumption estimated here is valid, then about $4 \%$ of the breast cancers in women in developed countries may be attributable to alcohol. The consumption of alcohol by most women in developed countries is relatively low, with about two-thirds consuming little or no alcohol each day. For women in developed countries who regularly drink alcohol, the lifetime risk of breast

\section{REFERENCES}

1 Hiatt RA, Bawol RD (1984) Alcoholic beverage consumption and breast cancer incidence. Am J Epidemiol 120: 676-683

2 Lê MG, Moulton LH, Hill C, Kramar A (1986) Consumption of dairy produce and alcohol in a case-control study of breast cancer. J Natl Cancer Inst 77: 633-636

3 Harvey EB, Schairer C, Brinton LA, Hoover RN, Fraumeni Jr JF (1987) Alcohol consumption and breast cancer. J Natl Cancer Inst 78: 657-661

4 La Vecchia C, Decarli A, Parazzini F, Gentil A, Negri E, Cecchetti G, Franceschi S (1987) General epidemiology of breast cancer in Northern Italy. Int J Epidemiol 16: $347-355$

5 Lee NC, Rosero-Bixby L, Oberle MW, Grimaldo C, Whatley AS, Rovira EZ (1987) A case-control study of breast cancer and hormonal contraception in Costa Rica. J Natl Cancer Inst 79: $1247-1254$

6 Willett WC, Stampfer MJ, Colditz GA, Rosner BA, Hennekens CH, Speizer FE (1987) Moderate alcohol consumption and the risk of breast cancer. $N$ Engl J Med 316: 1174-1180

7 Adami HO, Lund E, Bergstrom R, Meirik O (1988) Cigarette smoking, alcohol consumption and risk of breast cancer in young women. $\mathrm{Br} J$ Cancer 58: $832-837$

8 Rohan TE, McMichael AJ (1988) Alcohol consumption and risk of breast cancer. Int J Cancer 41: 695-699

9 Yuan J-M, Yu MC, Ross RK, Gao Y-T, Henderson BE (1988) Risk factors for breast cancer in Chinese women in Shanghai. Cancer Res 48: 19491953

10 Chu SY, Lee NC, Wingo PA, Webster LA (1989) Alcohol consumption and the risk of breast cancer. Am J Epidemiol 130: 867-877

11 La Vecchia C, Negri E, Parazzini F, Boyle P, Fasoli M, Gentile A, Franceschi S (1989) Alcohol and breast cancer: update from an Italian casecontrol study. Eur J Cancer Clin Oncol 25: 1711-1717

12 Meara J, McPherson K, Roberts M, Jones L, Vessey M (1989) Alcohol, cigarette smoking and breast cancer. Br J Cancer 60: 70-73

13 Mills PK, Beeson WL, Phillips RL, Fraser GE (1989) Prospective study of exogenous hormone use and breast cancer in Seventh-day Adventists. Cancer 64: $591-597$

14 Richardson S, de Vincenzi I, Pujol H, Gerber M (1989) Alcohol consumption in a case-control study of breast cancer in southern France. Int $J$ Cancer 44: $84-89$

15 Siskind V, Schofield F, Rice D, Bain C (1989) Breast cancer and breastfeeding: results from an Australian case-control study. Am J Epidemiol 130: $229-236$

16 Rosenberg L, Palmer JR, Miller DR, Clarke EA, Shapiro S (1990) A casecontrol study of alcoholic beverage consumption and breast cancer. Am J Epidemiol 131: 6-14

17 Ewertz M (1991) Alcohol consumption and breast cancer risk in Denmark. Cancer Causes and Control 2: 247-252 cancer is estimated to increase by about 0.7 per 100 women for each extra unit or drink of alcohol consumed on a daily basis. For example, the cumulative incidence of breast cancer by age 80 years is estimated to increase from 8.8 per 100 women who drink no alcohol to 10.1 or 100 who consume two alcoholic drinks daily and to 11.6 per 100 who consume four drinks daily. This excess risk should be considered in the context of the beneficial effects of alcohol, in moderation, on cardiovascular disease, and its harmful effects on cirrhosis and on cancers of the mouth, larynx, oesophagus and the liver. ${ }^{73,74}$

\section{ACKNOWLEDGEMENTS}

This review would not have been possible without the tens of thousands of women with and without breast cancer who took part in this research. Central pooling, checking and analysis of data was supported by the Cancer Research UK and the UNDP/UNFPA/ WHO/World Bank Special Programme of Research, Development and Research Training in Human Reproduction.

18 Sneyd MJ, Paul C, Spears GF, Skegg DCG (1991) Alcohol consumption and risk of breast cancer. Int J Cancer 48: $812-815$

19 Gapstur SM, Potter JD, Sellers TA, Folsom AR (1992) Increased risk of breast cancer with alcohol consumption in postmenopausal women. Am J Epidemiol 136: 1221 - 1231

20 Ursin G, Aragaki CC, Paganini-Hill A, Siemiatycki J, Thompson WD, Haile RW (1992) Oral contraceptives and premenopausal bilateral breast cancer: a case-control study. Epidemiology 2: 414-419

21 Wang Q-S, Ross RK, Yu MC, Ning J-P, Henderson BE, Kimm HT (1992) A case-control study of breast cancer in Tianjin, China. Cancer Epidemiol Biomarkers Prevent 1: $435-439$

22 Yang CP, Daling JR, Band PR, Gallagher RP, White E, Weiss NS (1992) Non contraceptive hormone use and risk of breast cancer. Cancer Causes Control 3: 475-479

23 Ferraroni M, Gerber M, Decarli A, Richardson S, Marubini E, Crastes de Paulet A, Pujol H (1993) HDL-cholesterol and breast cancer: a joint study in Northern Italy and Southern France. Int J Epidemiol 22: $772-780$

24 Friedenreich CM, Howe GR, Miller AB (1993) A cohort study of alcohol consumption and risk of breast cancer. Am J Epidemiol 137: 512-520

25 Katsouyanni K, Trichopoulou A, Stuver S, Vassilaros S, Papadiamantis Y, Bournas N, Skarpou N, Mueller N, Trichopoulos D (1994) Ethanol and breast cancer: an association that may be both confounded and causal. Int J Cancer 58: 356-361

26 Land CE, Hayakawa N, Machado SG, Yamada Y, Pike MC, Akiba S, Tokunaga M (1994) A case-control interview study of breast cancer among Japanese A-bomb survivors. II. Interactions with radiation dose. Cancer Causes Control 5: 167-176

27 Rookus MA, van Leeuwen FEfor the Netherlands Oral Contraceptives and Breast Cancer Study Group (1994) Oral contraceptives and risk of breast cancer in women aged $20-54$ years. Lancet 344: $844-851$

28 Smith SJ, Deacon JM, Chilvers CE (1994) Alcohol, smoking, passive smoking and caffeine in relation to breast cancer risk in young women. UK National Case-Control Study Group. Br J Cancer 70: $112-119$

29 White E, Malone KE, Weiss NS, Daling JR (1994) Breast cancer among young US women in relation to oral contraceptive use. J Natl Cancer Inst 86: $505-514$

30 Longnecker MP, Newcomb PA, Mittendorf R, Greenberg ER, Clapp RW, Bogdan GF, Baron J, MacMahon B, Willett WC (1995) Risk of breast cancer in relation to lifetime alcohol consumption. J Natl Cancer Inst 87: $923-929$

31 Longnecker MP, Paganini-Hill A, Ross RK (1995) Lifetime alcohol consumption and breast cancer risk among postmenopausal women in Los Angeles. Cancer Epidemiol Biomarkers Prevent 4: 721-725 
32 Primic-Zakelj M, Evstifeeva T, Ravnihar B, Boyle P (1995) Breast cancer risk and oral contraceptive use in Slovenian women aged 25 to 54 . Int J Cancer 62: $414-420$

33 van den Brandt PA, Goldbohm RA, van't VeerP (1995) Alcohol and breast cancer: results from the Netherlands Cohort Study. Am J Epidemiol 141: $907-915$

34 Levi F, Pasche C, Lucchini F, La Vecchia C (1996) Alcohol and breast cancer in the Swiss Canton of Vaud. Eur J Cancer 32A: 2108-2113

35 Morabia A, Bernstein M, Heritier S, Khatchatrian N (1996) Relation of breast cancer with passive and active exposure to tobacco smoke. Am J Epidemiol 143: $918-928$

36 Rossing MA, Stanford JL, Weiss NS, Habel LA (1996) Oral contraceptive use and risk of breast cancer in middle-aged women. Am J Epidemiol 144: $161-164$

37 Viladiu P, Izquierdo A, de Sanjosé S, Bosch FX (1996) A breast casecontrol study in Girona, Spain. Endocrine, familial and lifestyle factors. Eur J Cancer Prevent 5: 329-335

38 Bowlin SJ, Leske MC, Varma A, Nasca P, Weinstein A, Caplan L (1997) Breast cancer risk and alcohol consumption: results from a large casecontrol study. Int J Epidemiol 26: 915 -923

39 Clavel-Chapelon F, Dormoy N, Guibout C (1997) Wine, beer and tobacco consumption and the risk of breast cancer: results from a French casecontrol study. J Epidemiol Biostat 2: 95-104

40 Swanson CA, Coates RJ, Malone KE, Gammon MD, Schoenberg JB, Brogan DJ, McAdams M, Potischman N, Hoover RN, Brinton LA (1997) Alcohol consumption and breast cancer risk among women under age 45 years. Epidemiology 8: $231-237$

41 Thomas DB, Gao DL, Self SG, Allison CJ, Tao Y, Mahloch J, Ray R, Qin Q, Presley R, Porter P (1997) Randomized trial of breast self-examination in Shanghai: methodology and preliminary results. J Natl Cancer Inst 89: $355-365$

42 McCredie MRE, Dite GS, Giles GG, Hopper JL (1998) Breast cancer in Australian women under the age 40. Cancer Causes Control 9: 189-198

43 Ferraroni M, Decarli A, Franceschi S, La Vecchia C (1998) Alcohol consumption and risk of breast cancer: a multicentre Italian case-control study. Eur J Cancer 34: 1403-1409

44 Enger SM, Ross RK, Paganini-Hill A, Longnecker MP, Bernstein L (1999) Alcohol consumption and breast cancer oestrogen and progesterone receptor status. $\mathrm{Br}$ J Cancer 79: $1308-1314$

45 Hopper JL, Chenevix-Trench G, Jolley D, Dite GS, Jenkins MA, Venter DJ, McCredie MRE, Giles GG (1999) Design and analysis issues in a population-based case-control-family study of the genetic epidemiology of breast cancer, and the Co-operative Family Registry for Breast Cancer Families (CFRBCS). Monogr Nat Cancer Inst 26: 95-100

46 Magnusson C, Baron JA, Correia N, Bergstrom R, Adami H-O, Persson I (1999) Breast cancer risk following long-term oestrogen- and oestrogenprogestin-replacement therapy. Int J Cancer 81: 339-344

47 Million Women Study Collaborative Group (1999) The Million Women Study: Design and Characteristics of the Study Population. Breast Cancer Res 1: $73-80$

48 Gao Y-T, Shu XO, Dai Q, Potter J, Brinton L, Wen W, Sellers T, Kushi LH, Yuen ZX, Bostick R, Jin F, Zheng W (2000) Menstrual, reproductive factors and breast cancer risk in urban Shanghai, People's Republic of China. Int J Cancer 87: 295-300

49 Johnson KC, Hu J, Mao Ythe Canadian Cancer Registries Epidemiology Research Group (2000) Passive and active smoking and breast cancer risk in Canada, 1994-97. Cancer Causes Control 11: 211-221

50 Feigelson HS, Calle EE, Robertson AS, Wingo PA, Thun MJ (2001) Alcohol consumption increases the risk of fatal breast cancer. Cancer Causes and Control 12: $895-902$

51 Kropp S, Becker H, Nieters A, Change-Claude J (2001) Low and Moderate alcohol consumption and breast cancer risk by age 50 among women in Germany. Am J Epidemiol 154: 624-634

52 Thomas DB, Noonan EAand the WHO Collaborative Study of Neoplasia and Steroid Contraceptives (1993) Breast cancer and prolonged lactation. Int J Epidemiol 22: 619-626

53 Vessey MP, McPherson K, Doll R (1981) Breast cancer and oral contraceptives: findings in Oxford-Family Planning Association contraceptive study. Br Med J 282: 2093-2094
54 Pike MC, Henderson BE, Krailo MD, Duke A, Roy S (1983) Breast cancer in young women and use of oral contraceptives: possible modifying effect of formulation and age at use. Lancet ii: 926-930

55 Nomura AMY, Hirohata T, Kolonel LN, Hankin JH, Lee J, Stemmermann G (1985) Breast cancer in caucasian and Japanese women in Hawaii. Nat Cancer Inst Monogr 69: 191 - 196

56 Hislop TG, Coldman AJ, Elwood JM, Skippen DH, Kan L (1986) Relationship between risk factors for breast cancer and hormonal status. Int J Epidemiol 15: 469-476

57 Kay CR, Hannaford PC (1988) Breast cancer and the pill - a further report from the Royal College of General Practitioners' oral contraception study. Br J Cancer 58: $675-680$

58 Ravnihar B, Primic Zakelj M, Kosmelj K, Stare J (1988) A case-control study of breast cancer in relation to oral contraceptive use in Slovenia. Neoplasma 35: 109-121

59 Lee HP, Gourley L, Duffy SW, Esteve J, Lee J, Day NE (1992) Risk factors for breast cancer by age and menopausal status: a case-control study in Singapore. Cancer Causes Control 3: 313-322

60 Ngelangel CA, Lacaya LB, Cordero C, Laudico AV (1994) Risk factors for breast cancer among Filipino women. Phil J Internal Med 32: 231 - 236

61 Hirose K, Tajima K, Hamajima N, Inoue M, Takezaki T, Kuroishi T, Yoshida M, Tokudome S (1995) A large scale, hospital based case-control study of risk factors of breast cancer according to menopausal status. Jpn J Cancer Res 86: 154

62 Thomas HV, Key TJ, Allen DS, Moore JW, Dowsett M, Fentiman IS Wang DY (1997) Reversal of relation between body mass and endogenous estrogen concentrations with menopausal status. J Natl Cancer Inst 89: $396-397$

63 Garrett PA, Hulka BS, Farber RA (2000) Racial differences in the association of rare HRAS alleles and breast cancer. Am J Epidemiol 138: 599-599

64 Collaborative Group on Hormonal Factors in Breast Cancer (1997) Breast cancer and hormone replacement therapy: collaborative reanalysis of data from 51 epidemiological studies of 52705 women with breast cancer and 108411 women without breast cancer. Lancet 350: 1047-1059

65 Collaborative Group on Hormonal Factors in Breast Cancer (1996) Breast cancer and hormonal contraceptives: further results. Contraception 54(Suppl 3): 1S-106S

66 Peto R, Pike M, Armitage P, Breslow NE, Cox DR, Howard SV, Mantel N, McPherson K, Peto J, Smith PG (1976) Design and analysis of randomized clinical trials requiring prolonged observation of each patient. $\mathrm{Br}$ J Cancer 34: 585-612

67 Easton DF, Peto J, Babiker AGAG (1991) Floating absolute risk: an alternative to relative risk in survival and case-control analysis avoiding an arbitrary reference group. Stat Med 10: $1025-1035$

68 Doll R, Peto R, Hall E, Wheatley K, Gray R (1994) Mortality in relationship to consumption of alcohol: 13 years' observation of male British doctors. Br Med I 309: 911 -918

69 Fletcher CM, Peto R, Tinker CM, Speizer FE (1976) The natural history of chronic bronchitis and emphysema Oxford: Oxford University Press

70 Parkin DM, Whelan SL, Ferlay J, Raymond L, Young J (1997) Cancer Incidence in Five Continents, Vol VII: Lyon: IARC Scientific Publication

71 Doll R, Peto R (1978) Cigarette smoking and bronchial carcinoma: dose and time relationships among regular smokers and lifelong non-smokers. J Epidemiol Comm Health 32: 303-313

72 Dorgan JF, Baer DJ, Albert PS, Judd JT, Brown ED, Corle DK, Campbell WS, Hartman TJ, Tejpar AA, Clevidence BA, Giffen CA, Chandler DW, Stanczyk FZ, Taylor PR (2001) Serum hormones and the alcohol-breast cancer association in postmenopausal women. J Natl Cancer Inst 93: $710-715$

73 Thun MJ, Peto R, Lopez AD, Monaco JH, Henley J, Heath Jr CW, Doll R (1997) Alcohol consumption and mortality among middle-aged and elderly US adults. N Engl J Med 337: 1705-1714

74 IARC monographs on the evaluation of carcinogenic risks to human (1988) Alcohol drinking Vol. 44: Lyon, France: International Agency for Research on Cancer 
APPENDIX I. - COLLABORATORS (in alphabetical order of institution, study name, or location)

Aichi Cancer Research Institute, Nagoya, Japan: N Hamajima, K Hirose, K Tajima; Albert Einstein College of Medicine, NY, USA: T Rohan; American Cancer Society, GA, USA: EE Calle, CW Jr Heath; Atlanta, Emory University, GA, USA: RJ Coates, JM Liff; Aviano Cancer Center, Pordenone, Italy: R Talamini; Mahidol University, Bangkok, Thailand: N Chantarakul, S Koetsawang, D Rachawat; Breast Tumor Collaborative Study, Johns Hopkins University, MD, USA: A Morabia, L Schuman, W Stewart, M Szklo; University of Queensland, Brisbane, Australia: C Bain, F Schofield, V Siskind; British Columbia Cancer Agency, BC, Canada: P Band, AJ Coldman, RP Gallagher, TG Hislop, P Yang; Cancer Research Center, University of Hawaii, Hawaii, USA: LM Kolonel, AMY Nomura; Canadian Cancer Registries Epidemiology Research Group, Canada: J Hu, KC Johnson, Y Mao; Catalán Institut of Oncology, Barcelona, Spain: S De Sanjosé; Centers for Disease Control \& Prevention, GA, USA: N Lee, P Marchbanks, HW Ory, HB Peterson, HG Wilson, PA Wingo; Central Institute of Cancer Research, Berlin, Germany: K Ebeling, D Kunde, P Nishan; Centre for Genetic Epidemiology, University of Melbourne, Melbourne, Australia: JL Hopper; Channing Laboratory, Brigham and Women's Hospital, Harvard Medical School, MA, USA: G Colditz for Nurses' Health Study Research Group; Chennai Cancer Institute, Madras, India: V Gajalakshmi; Chiang Mai University, Chiang Mai, Thailand: N Martin, T Pardthaisong, S Silpisornkosol, C Theetranont; Chulalongkorn University, Bangkok, Thailand: B Boosiri, S Chutivongse, P Jimakorn, P Virutamasen, C Wongsrichanalai; Danish Cancer Society, Aalborg, Denmark: M Ewertz; Department of Medical Epidemiology, Karolinska Institute, Stockholm, Sweden: HO Adami, L Bergkvist, C Magnusson, I Persson; Deutsches Krebsforschungszentrum, Heidelberg, Germany: J Chang-Claude; University of Otago, Dunedin, New Zealand: C Paul, DCG Skegg, GFS Spears; European Institute of Oncology, Milan, Italy: P Boyle, T Evstifeeva; Fred Hutchinson Cancer Research Center, WA, USA: JR Daling, WB Hutchinson, K Malone, EA Noonan, JL Stanford, DB Thomas, NS Weiss, E White; French Multicentre Breast Study, INSERM, Villejuif, France: N Andrieu, A Brêmond, F Clavel, B Gairard, J Lansac, L Piana, R Renaud; Girona Cancer Registry, Girona, Spain: A Izquierdo, P Viladiu; Hospital General de Mexico, Mexico City, Mexico: HR Cuevas, P Ontiveros, A Palet, SB Salazar; Hospital Universitario, Cali, Colombia: N Aristizabal, A Cuadros; Icelandic Cancer Society, Reykjavik, Iceland: L Tryggvadottir, H Tulinius; INSERM, Institut Gustave-Roussey, Villejuif, France: A Bachelot, MG Lê; Institute of Cancer Research, Sutton and London School of Hygiene and Tropical Medicine, UK: J Peto; International Agency for Research in Cancer, Lyon, France: S Franceschi; Israel Chaim Sheba Medical Centre, Tel-Hashomer, Israel: F Lubin, B Modan, E Ron, Y Wax; Kaiser Permanente, CA, USA: GD Friedman, RA Hiatt; Institut universitaire de medecine sociale et preventive, Lausanne, Switzerland: F Levi; Cancer Research UK Genetic Epidemiology Laboratory, Leeds, UK: T Bishop; Institute of Oncology, Ljubljana, Slovenia: K Kosmelj, M PrimicZakelj, B Ravnihar, I Stare; Loma Linda University, CA, USA: WL Beeson, G Fraser; Cancer Research UK Department of Mathematics, Statistics \& Epidemiology, London: RD Bulbrook, J Cuzick, SW Duffy, IS Fentiman, JL Hayward, DY Wang; London School of Hygiene \& Tropical Medicine, London, UK: AJ McMichael, K McPherson; Long Island Breast Cancer

APPENDIX II. - References to epidemiological studies of breast cancer and alcohol and tobacco consumption and to reviews of the topic

(This can be viewed on the website www.bjcancer.com)
Study, NY, USA: RL Hanson, MC Leske, MC Mahoney, PC Nasca, AO Varma, AL Weinstein; University Hospital, Lund, Sweden: TR Moller, H Olsson, J Ranstam; Maastricht University, Maastricht, The Netherlands: RA Goldbohm, PA van den Brandt; University of Philippines, Manila, Philippines: RA Apelo, J Baens, JR de la Cruz, B Javier, LB Lacaya, CA Ngelangel; Istituto 'Mario Negri', Milan, Italy: C La Vecchia, E Negri; Istituto Nazionale Tumori, Divisione di Statistica Medica e Biometria, Milan, Italy: E Marubini; Istituto di Statistica Medica e Biometria, Milan, Italy: M Ferraroni; Montpellier Cancer Centre \& INSERM, Montpellier, France: M Gerber, S Richardson, C Segala; Nairobi Centre for Research in Reproduction, Nairobi, Kenya: D Gatei, P Kenya, A Kungu, JG Mati; National Cancer Institute, MD, USA: LA Brinton, R Hoover, C Schairer; National Institute of Child Health \& Human Development, MD, USA: R Spirtas; National University of Singapore, Singapore: HP Lee; The Netherlands Cancer Institute, Amsterdam, The Netherlands: MA Rookus, FE van Leeuwen for the Netherlands Oral Contraceptives and Breast Cancer Study Group; New Jersey State Department of Health, NJ, USA: JA Schoenberg; New South Wales Cancer Council, Sydney, Australia: M McCredie; Columbia University School of Public Health, NY, USA: MD Gammon; Ontario Cancer Treatment \& Research Foundation, Ontario, Canada: EA Clarke; Department of Public Health \& Primary Care, Oxford, UK: L Jones, A Neil, M Vessey, D Yeates; Cancer Research UK Epidemiology Unit, Oxford, UK (Secretariat): P Appleby, E Banks, V Beral, D Bull, B Crossley, A Goodill, J Green, C Hermon, T Key, N Langston, C Lewis, G Reeves; Cancer Research UK/MRC/BHF Clinical Trial Service Unit \& Epidemiological Studies Unit, Oxford, UK: R Collins, R Doll, R Peto; Radiation Effects Research Foundation, Hiroshima, Japan: K Mabuchi, D Preston; Royal College of General Practitioners Oral Contraception Study, London, UK: P Hannaford, C Kay; University of Costa Rica, San Jose, Costa Rica: L Rosero-Bixby; Shanghai Cancer Institute, Shanghai, China: YT Gao, F Jin, J-M Yuan; Shanghai Institute of Planned Parenthood Research, Shanghai, China: HY Wei, T Yun, C Zhiheng; Department of Public Health, Sydney, Australia: G Berry, J Cooper Booth, T Jelihovsky, R MacLennan, R Shearman; Tianjin Cancer Institute, Tianjin, China: Q-S Wang; Department of Public Health Sciences, Toronto, Canada: CJ Baines, AB Miller, C Wall; Tromso University, Tromso, Norway: E Lund, H Stalsberg; Vanderbilt University, TN, USA: XO Shu, W Zheng; University of Athens Medical School, Athens, Greece: K Katsouyanni, A Trichopoulou, D Trichopoulos; University of Chile, Santiago, Chile: A Dabancens, L Martinez, R Molina, O Salas; University of Edinburgh, Edinburgh, UK: FE Alexander; University of Minnesota School of Public Health, MN, USA: K Anderson, AR Folsom on behalf of the Iowa Women's Health Study; University of North Carolina at Chapel Hill, School of Public Health, NC, USA: BS Hulka; University of Nottingham, Nottingham, UK: CED Chilvers; University of Southern California, LA, USA: L Bernstein, S Enger, RW Haile, A Paganini-Hill, MC Pike, RK Ross, G Ursin, MC Yu; University of Wisconsin Comprehensive Cancer Center, WI, USA: MP Longnecker, $\mathbf{P}$ Newcomb for the 4 State Study; Vasteras, Sweden: L Bergkvist; World Health Organisation, Geneva, Switzerland: A Kalache; World Health Organisation, UNDP/UNFPA/WHO/World Bank Special Programme of Research, Development and Research Training in Human Reproduction, Geneva, Switzerland: TMM Farley, S Holck, O Meirik.

Analysis and writing committee: Beral V, Bull D, Doll R, Peto R, Reeves G Steering committee: Skegg D (Chairman), Colditz G, Hulka B, La Vecchia C, Magnusson C, Muller A, Peterson B, Pike M, Thomas D, Van Leeuven $M$.

APPENDIX IV.-Results on the relation between past smoking and breast cancer in women who reported drinking no alcohol

(This can be viewed on the website www.bjcancer.com)

\section{APPENDIX III.-Results on the relation between current smoking and breast cancer in women who reported drinking no alcohol}

(This can be viewed on the website www.bjcancer.com) 